\title{
Addressing Complex Problems: Using Authentic Audiences and Challenges to Develop Adaptive Leadership and Socially Responsible Agency in Leadership Learners
}

\author{
Anthony C. Andenoro \\ Matthew J. Sowcik \\ Teresa C. Balser
}

\begin{abstract}
Complex and adaptive challenges threaten human well-being and sustainability. However, our leadership graduates often lack the capacity and or commitment to address these challenges in a meaningful way. This paper details a five-year study exploring the impact of an interdisciplinary undergraduate course on the development of global capacities, complex Adaptive Leadership, Socially Responsible Agency, and systems thinking. The course instructors used innovative and intentionally divergent learning methods to challenge students to serve as stewards of their own knowledge and facilitators of their own learning through the confrontation of authentic and complex challenges. The researchers note transferable qualitative findings that demonstrate the profound impact of the noted leadership learning experience on the development of Socially Responsible Agency, along with Adaptive Leadership capacity and systems thinking.
\end{abstract}

\section{Introduction}

Leadership educators of the past facilitated leadership learning through the dissemination of theory and facilitation of activities aimed at applying the theory. However, the landscape of leadership education has shifted considerably. Competing priorities and an ever-changing array of issues create significant challenges for leadership educators aspiring to develop the next generation of leaders (Andenoro, Allen, Haber-Curran, Jenkins, Sowcik, Dugan, \& Osteen, 2013). Andenoro et al. (2013) defined leadership education as:

The pedagogical practice of facilitating leadership learning in an effort to build human capacity and is informed by leadership theory and research. It values and is inclusive of both curricular and co-curricular educational contexts (p. 3).

The intentional inclusion of "human capacity" within this definition promotes the addition of new educational paradigms and methodologies that go beyond conventional leadership education and more importantly, develop learner capacities and dispositions essential for effective leadership practice. Complex adaptive challenges without solutions present themselves on almost a daily basis. This requires leadership educators to cultivate critical and creative thinking capacity and agency along with other foundational elements of the Adaptive Leadership practice (Heifetz \& Linsky, 2002) and complexity leadership (Lichtenstein, UhlBien, Marion, Seers, Orton, \& Schreiber, 2006) in their learners. Agency for the purposes of this paper can be defined as: 
A temporally embedded process of social engagement, informed by the past (in its habitual aspect), but also oriented toward the future (as a capacity to imagine alternative possibilities) and toward the present (as a capacity to contextualize past habits and future project within the contingencies of the moment) (Emirbayer \& Mische, 1998, p. 963).

Further organizations and communities promoting practice aimed at maintaining profit generation, ethical standards, and community and environmental sustainability will require socially responsible employees. Social Responsibility or "the extent to which and the way in which a person is consciously responsible for and accounts for his or her action, non-actions, and their impact on given stakeholders" (Banerjee, 2006, p.31) provides the foundation for our learners to serve in these organizations and contribute to our communities.

To address the challenges associated with an ever-growing worldwide population, instructors and researchers at a large land-grant institution in the United States have initiated an interdisciplinary certificate program entitled the Global Leadership \& Change (GLC) Certificate in coordination with a larger academic and student development program, [insert name of program here]. The GLC program brings interdisciplinary undergraduate students, industry leaders, policy makers, extension professionals, and corporate sponsors together in an innovative and integrated fashion aimed at one overarching goal, to address the problems associated with a growing global population that is projected to exceed 9.725 billion people by the year 2050 . This four-course, 10-credit hour, certificate program integrates social and natural science content to develop complex adaptive thinking and potential solutions for addressing the problems associated with large-scale global population fluctuation.

The GLC program is differentiated by how leadership learning is facilitated within the coursework. In traditional leadership courses, instructors often provide learners with content, which is then linked as a solution to a given problem. However, the courses within this program are very different and extend well beyond traditional educational parameters. Instructors start with the problem, offering it to the learners for consumption. Content experts from a broad spectrum of disciplines at the university further articulate the problem for the students and industry and community stakeholders throughout the semester through guest lectures. Instructors then use incisive questioning (Kline, 1999) and the innovative F.A.C.E. Method (C, which stands for Foundational Awareness, Authentic Engagement, Connective Analysis, and Empowerment and Change, grounded in Emotionally Engaged Thinking (Stedman \& Andenoro, 2015) to encourage students and stakeholders to embrace the problems and their ambiguity, and begin to work through the variables intertwined within the complexity of the problems. Along with incisive questioning, the F.A.C.E. Method (C), creates a foundation for the learners to develop integrated, systems-focused solutions for real problems. Learners are then asked to explore their community in an effort to examine potential barriers for solutions and adoption of the innovative solutions that exist based on public perceptions. This provides a powerful snapshot of the complexity associated the problem. Learners become frustrated with the problem and its complexity, but they persist in attempting to solve the problem, because they have developed ownership of the knowledge that surrounds the problem. The course culminates in students presenting collaborative solutions in teams to state and national policy makers, industry leaders, and corporate sponsors. The authentic audiences and authentic challenges present in the leadership learning context, have a profound impact on the learners and could potentially have a 
profound impact on how the learners impact the world.

To date, the findings associated with the impact of the first course within the certificate on the students have been compelling. Students demonstrate perspectives grounded in social responsibility and agency, along with Adaptive Leadership capacity and systems thinking. The following provides a qualitative snapshot of the context within the first course, Global Uncertainty, and the consistent emergent themes that demonstrate impact. Transferable findings can be applied to like contexts and the implementation of the presented educational methodologies allow for the development of human capacity and complex adaptive problem solving skills in leadership learners.

\section{Literature Review}

The global population is growing at an exponential rate. Specifically, the global population will increase by $23 \%$ by 2050 (United Nations, Department of Economic and Social Affairs, Population Division, 2015). To sustainably move from 7.5 billion to 9.725 billion will require significant innovation, leadership, and complex adaptive problem solvers. While the complex problems that stem from global population growth are plentiful, the six main issues stemming from the growth include space, agricultural yield, natural resource management, energy production and consumption, climate change, and global health (Andenoro, Baker, Stedman, \& Weeks, 2016; Stedman \& Andenoro, 2015). Space will become a premium as 70\% of our global population will be living in cities by the year 2050 (United Nations Human Settlement Program, 2015). This causes urban sprawl resulting in the reduction of agricultural land and the number of traditional laborers that reside in rural areas. This leads to the second issue, agricultural yield. Our global population will need $70 \%$ more food to meet the needs of our population in 2050 (Alexandratos \& Bruinsma, 2012). Andenoro, et al. (2016) and Brown (2012) note that this is happening for three reasons, (a) weather patterns, (b) soil degradation and desertification, and (c) mismanagement of water. Concurrently the third issue is natural resource management. In addition to the mismanagement of water, over mining and excessive drilling has led to the elimination of valued minerals from the planet (Berger \& Finkbeiner, 2013). The fourth issue is energy. To meet the needs of 9.725 billion people, energy production will need in increase by 300\% (Emmott, 2013). This will far exceed current alternative energy and traditional fossil fuel practices and require innovative and collaborative solutions. The fifth issue is climate change. Climate change is happening at an accelerated pace as the carbon threshold for the atmosphere has exceeded 400 ppm and human behavior (i.e., reduction of Braśilian Rainforest for timber and agricultural industries) continues to be a concern (McCoy, Montgomery, Arulkumaran, \& Godlee, 2014). Finally, global health and our ability to create collaborative partnerships among granting organizations (e.g., World Health Organization or Gates Foundation), local health care administrators (e.g., Ministry of Health for the given context or the Center for Disease Control), and local providers and community health workers will continue to be growing needs.

While self-awareness is the foundation for addressing complex problems (Andenoro, et al. 2016; Andenoro, Popa, Bletscher, \& Albert, 2012; Sowcik, Andenoro, McNutt, \& Murphy, 2015), Adaptive Leadership provides a powerful tool for addressing and mitigating these issues (Heifetz \& Linsky, 2002; Heifetz, Grashow, \& Linsky, 2009; Lewin \& Regine, 2003; 
Lichtenstien, et al., 2006; Yukl \& Mahsud, 2010). Adaptive Leadership is the capacity to adapt to "changes in societies, markets, customers, competition, and technology around the globe [that] are forcing organizations to clarify their values, develop new strategies, and learn new ways of operating" (Heifetz \& Laurie, 1997, p. 124). Adaptive Leadership is critical to understanding the complexity that leadership learners face in real world settings. Lichtenstein, Uhl-Bien, Marion, Seers, Orton, and Schreiber (2006) write that "traditional, hierarchical views of leadership are less and less useful given the complexities of our modern world" (p.2). Hence, it becomes imperative for leadership educators to shift to innovative educational methods that explore the complexity of the problems leadership learners will face in the real world. In addition, educational initiatives should create dynamic and collaborative spaces for diverse stakeholders to transcend their individual capacity leading to knowledge creation and new epistemologies (2006). Through reflection and understanding that are inherent within the practice of Adaptive Leadership, learners can develop the perspective for addressing complex problems and promoting innovation. Along with this, complexity leadership (Lichtenstein, et al., 2006; Marion \& Uhl-Bien, 2001) creates a foundation for systems thinking which allows for understanding complex problems and the interactive dynamics within them, networked agents, and how emergent events stem from organizational interactions within given contexts (Uhl-Bien \& Marion, 2008). Complexity and Adaptive Leadership create an in-tandem response to addressing complex problems. The approach of complexity leadership is grounded in the practice of influencing and fostering conditions that develop organizational capacity, focus on understanding the patterns of complexity, and manipulate situations of complexity to achieve sustainable outcomes (Marion \& Uhl-Bien, 2003). When coupled with Adaptive Leadership, which includes the practice of accepting the disequilibrium of the system (Heifetz \& Linsky, 2002) and promoting strategic productivity within that system, learners gain a powerful process for addressing complex problems.

However, understanding complex problems is not enough. Learners must develop the capacity for addressing complex problems. This idea is intimately linked to agency. Agency, as conceptualized by Emirbayer and Mische (1998) is grounded in the resulting action that stems from context for the past, understanding for the present, and foresight for the future surrounding a given issue. As a temporally embedded process of social engagement (1998), agency provides learners with a propensity to act. Social responsibility is also a critical piece of this process. Zadek, Forstater, and Yu (2012) write that social responsibility actively engages in the innovation for offerings and operations that create distinctive value for organizations and society. When agency is coupled with social responsibility, or a personal investment in the well-being of others and the planet (Berman, 1990), learners have a foundation for morally addressing complex problems.

As noted in the introduction, incisive questions (Kline, 1999) and the F.A.C.E Method (C) (Stedman \& Andenoro, 2015) can create an educational environment that promotes the development of Adaptive Leadership and agency for addressing complex problems. Incisive questioning leverages the power of intentionally designed questions to address psychological embedded barriers in the learners. Rooted in counseling psychology and psychotherapy, an incisive question removes the limiting assumption from the learners' thinking and replaces it with a freeing one (1999). From a practical standpoint, an incisive question is a compound question composed of two parts, (a) a statement aimed at removing the limiting assumption and (b) a question that refocuses the learner on the given problem. These questions are effective 
because they are simple and pointed (1999).

The F.A.C.E. Method (C) (Stedman \& Andenoro, 2015), grounded within the tenets of neuroscience and psychotherapy, creates a foundation for behavioral shifts via intentionally constructed learning environments. Through purposive questioning aimed at unpacking learner experience and emotions, ownership can be cultivated in the learner. When linked to complex problems, this process and the accompanying line of questioning can form powerful connections and establish ownership and efficacy for learners surrounding the identified problems. Additionally, the learners' perspectives are deepened through this process, as systems thinking creates a foundation for decision making with respect to complex problems. The process "promotes a system's thinking approach that incorporates emotions as the catalyst for positive decision making" (Stedman \& Andenoro, 2015, p. 151), and ultimately leads to Emotionally Engaged Thinking for the mitigation of complex problems.

When used in conjunction with the previously listed innovative teaching methods, the presence and engagement of industry professionals and policy-makers (authentic audience) and real world problems (authentic challenges), can also have a powerful effect on the leadership learning environment. Specifically, students engaging with authentic audiences demonstrate a propensity to integrate fundamental industry perspectives and skills while being equipped with real-world experience (Hobbs \& Tsang, 2014). Further, the use of authentic audiences replete with authentic challenges from present day industry will become increasingly important. As the complexity of systems and complex issues grow, higher educational institutions need to not only keep up with the new knowledge of these systems but also utilize industry professionals in the training of students (2014). Kayes, Kayes, and Kolb (2005) note that authentic audiences and challenges create purpose and context for learners. Further the purpose and context created leads to sustainable engagement in the learning context (Kolb, 2014). This becomes critical as leadership educators attempt to develop Adaptive Leadership capacity and Socially Responsible Agency grounded in sustainable solutions for complex problems.

\section{Methods}

Context. Interdisciplinary undergraduates representative of 29 different majors and 10 of the 11 undergraduate colleges at a large land grant institution in the southern United States selfselected and enrolled in the first course offering within the GLC program between Fall 2013 and Fall 2017 semesters (i.e., five total course sections). The learners were $68 \%$ female and $32 \%$ male and included first-year students though graduating seniors. From the total enrollees $(\mathrm{N}=245), 200$ respondents were purposively sampled to participate in qualitative data collection efforts and provide thick, rich description to gain insight into the context and its perceived impact on the students' learning. Student respondents $(n=191)$ provided perspectives yielding a transferable snapshot of the context.

The following research objectives guided the researchers' data collection efforts:

1. Explore the learners' self-perceived impact of the course on their complex Adaptive Leadership capacity

2. Explore the learners' self-perceived impact of the course on their capacity for systems thinking 
3. Explore the learners' self-perceived impact of the course on their agency for addressing the complex problems

4. Explore the learners' self-perceived of the key determinants of the course learning outcomes

Data Collection. Primary data for this study were collected in three ways to ensure for triangulation (Flick, 1992). First, a content analysis of respondent writing samples was conducted to make replicable and valid inferences from the data to the context (Krippendorff, 2012). Second, student respondents provided perspectives regarding the impact of the course via focus groups. Finally, student respondents participated in personal interviews providing summative perspectives of the course, retention of course competencies, and application of student attitudes and dispositions. Focus groups and personal interviews were audio recorded and referential adequacy materials were maintained to ensure for trustworthiness (Erlandson, Harris, Skipper, \& Allen, 1993). Respondents signed consent forms and perceptions were coded and reported in aggregate form to ensure for confidentiality.

Data Analysis. Data were analyzed using the constant comparative method (Glaser \& Strauss, 1967). This generated theoretical properties of the categories providing an understanding of the data and its relation to and effect on other categories (Erlandson, Harris, Skipper, \& Allen, 1993). The initial analysis of the data included reading and determining reoccurring themes throughout the data. The thick rich description of the data set allowed for inductive analysis leading to the discovery of patterns, themes, and categories. After the initial analysis, a team of researchers met to discuss the findings and engaged in a peer debriefing process whereby initial findings were vetted and further direction was provided regarding the trajectory of the research effort.

Similarities emerged in responses among respondents. These data similarities generated identifiable categories within each objective area. The defining rule for the constant comparative method is "while coding an incident for a category, compare it with the previous incidents in the same and different groups coded in the same category" (Glaser \& Strauss, 1967, p. 106). Data were coded into emergent categories and through constant comparison of the categories and their properties, the researchers developed theoretical perspectives about the contexts. As a key piece of the constant comparative data analysis process, open and axial coding (Lincoln \& Guba, 1985) were used to explore the context for distinct concepts and categories with respect to the qualitative data. Open coding is concerned with identifying, naming, categorizing and describing phenomena found in the text (Corbin \& Strauss, 2008) and allowed us to identify the overarching elements of the context. Axial coding was then used to identify causal relationships and phenomena that demonstrate understanding for why the respondents were impacted by the course and educational methodologies.

Throughout the data collection and analysis process trustworthiness was addressed and maintained. An audit trail was maintained throughout the data analysis and member checks were conducted with the respondents to allow for verification of data. This provided respondents with the opportunity to correct or clarify any recorded statements. 
Data Treatment. The first course within the GLC program is grounded in the literature aimed at the development of complex Adaptive Leadership capacity within leadership learners. Instructors teaching the first course within the GLC program develop complex Adaptive Leadership capacity via four intentionally designed educational methodologies. The first, incisive questioning (Kline, 1999) “removes the limiting assumptions, freeing [the learner's] mind to think afresh" (p. 54). By removing the limiting assumptions, or why a particular solution will not work, the learners are able to access their creative process and think critically about the given problem and its surrounding context. This process becomes paramount to developing a solution, because the problems that the learners are asked to solve within the course do not have answers. When learners are open to dissecting the given problems and potential solutions without bias, they begin to understand how they can take parts from various solutions to create more holistic solutions. Incisive questions have two functional pieces, the assertion of a positive assumption and the redirection of the learner's attention back to the issue or goal (1999). The following provides an example of an incisive question that is used at the beginning of the course: "if you knew that you were as intelligent as anyone out there working on this issue, how would you begin to address the issue?" This question subtly identifies the learner as an "expert" giving him or her the confidence to succeed and assume his or her newly found responsibility. Additionally, the question refocuses the learner's attention on the complex adaptive problem.

The F.A.C.E. Method (C, the means leading to Emotionally Engaged Thinking (Stedman \& Andenoro, 2015), is the second educational method used to develop Socially Responsible Agency and complex Adaptive Leadership thinking in leadership learners. F.A.C.E. first calls for the examination of the setting and factors influencing the decision. This is known as Foundational Awareness. Once this has been achieved, learners can begin to fully engage in the problem, which Stedman and Andenoro term Authentic Engagement. Through systems thinking and analysis, learners begin to form connections across various disciplines and systems. This is known as Connective Analysis, which ultimately leads to a shift in attitudes, perceptions, and the accompanying behavioral changes known as Empowerment and Change. This creative approach to bi-lateral decision-making aimed at empowerment and efficiency increases results in leadership learners and develops an innovative foundation for organizational development (2015).

The final two educational methods used in the class are authentic audience and authentic challenge (Andenoro, Bigham, \& Balser, 2014; Balser, Andenoro, \& Bigham, 2014). Although the idea of the "real world" or authentic audience and challenge is rooted in experiential learning (Estes, 2004; Miettinen, 2000; Katula \& Threnhauser, 1999; Carver, 1996; Giles \& Eyler, 1994; Kolb, 1984; Dewey; 1938), there is a significant gap in the literature with respect to these two terms. Understanding this, for the practical purposes of this paper, authentic audience can be defined as community or corporate based stakeholders external to the university system who hold decision-making capacity with respect to a given problem. An authentic challenge can be defined as a current dynamic problem or issue, whose solution can have tangible application within human contexts. Authentic challenges can be both technical and linear or complex and interdependent. The inclusion of authentic audiences and authentic challenges can provide the foundation for the development of complex adaptive thinkers and potential leaders equipped with the desire to initiate sustainable change in complex environments (Andenoro, Bigham, \& Balser, 2014). 


\section{Findings}

The findings for the qualitative analysis, inclusive of constant comparative and content analyses, are provided in the narrative form. This is intuitive and aligns with the grounded theory approach presenting a multitude of perspectives and a snapshot of the context (Charmaz, 2014). The emergent grounded theory provides fit, workability, relevance, and modifiability (Glaser, 1978) to ensure for transferability to like contexts. Further, the grounded theory provides credibility, originality, resonance, and usefulness (Eriksson \& Kovalainen, 2008; Charmaz, 2014) to the study.

Open coding for respondent perceptions within the analysis process allowed for overarching themes to emerge leading to grounded theory. Specifically, our analyses demonstrated three main overarching themes focusing on the capacities gained from the course and the accompanying methodologies - (a) Adaptive Leadership capacity (87\% of respondents); (b) systems thinking (76\% of respondents); and (c) Socially Responsible Agency (71\% of respondents).

Further axial coding within the constant comparative and content analyses identified five sub-themes within the overarching theme of Adaptive Leadership capacity. These include heightened levels of (a) self-awareness (89\% of respondents), (b) intercultural competence (67\% of respondents), (c) desire for collaboration (73\% of respondents), (d) effective communication ( $92 \%$ of respondents), and (e) high internal locus of control (90\% of respondents) due to the course and accompanying methodologies. Two other themes emerged naturalistically as key determinants for the developmental outcomes, (a) authentic audience and (b) authentic challenge. Sixty-two percent of respondents noted the powerful role of authentic audience and authentic challenge in the understanding and addressing complex problems. The following provides a frequency table illustrating the themes that naturalistically emerged from the data analyses.

Table 1.

Frequency of Respondent Perceptions.

\begin{tabular}{llll}
\hline Theme & $\begin{array}{l}\text { Number of } \\
\text { Respondents }\end{array}$ & Total Respondents & Frequency \\
\hline $\begin{array}{l}\text { Adaptive Leadership } \\
\text { Capacity }\end{array}$ & 166 & 191 & $87 \%$ \\
\hline Self-Awareness* & 170 & 191 & $89 \%$ \\
\hline $\begin{array}{l}\text { Intercultural } \\
\text { Competence* }\end{array}$ & 128 & 191 & $67 \%$ \\
\hline $\begin{array}{l}\text { Desire for Collaboration* } \\
\text { Effective }\end{array}$ & 139 & 191 & $73 \%$ \\
$\begin{array}{l}\text { Communication* } \\
\begin{array}{l}\text { Internal Locus of } \\
\text { Control* }\end{array}\end{array}$ & 176 & 191 & $92 \%$ \\
\hline Systems Thinking & 145 & 191 & $90 \%$ \\
\hline $\begin{array}{l}\text { Socially Responsible } \\
\text { Agency }\end{array}$ & 136 & 191 & $76 \%$ \\
\hline $\begin{array}{l}\text { Authentic Challenge \& } \\
\text { Audience }\end{array}$ & 118 & 191 & $62 \%$ \\
\hline
\end{tabular}

*Sub-Theme within Adaptive Leadership Capacity 
Development of Adaptive Leadership Capacity. Respondents identified that the course and non-traditional educational methodologies are contributing to the development of Adaptive Leadership and dispositions in five main areas: self-awareness, intercultural competence, collaboration, communication, and locus of control. Specifically, a preponderance of respondents noted that following the course they could be more intentional about reflection, as a means of developing perspective within complex situations (87\%). Further, respondents detailed that they were able to understand the roles of personal and organizational change in addressing complex problems within the context of the class. "If I understand myself and the biases I have, I can watch for these and embrace the changes that leads us to a better place for our world" (RB31). These perspectives extended beyond the classroom, as respondents shared that their understanding of complex problems and their ability to address them were indelibly tied to their ability to engage the diverse perspective of those around them to create sustainable solutions. "When I consider the complex problems presented in the class, I realize that I will need additional perspectives to fully understand them and come up with solutions" (RD12). The following sub-themes emerged via axial coding and further illustrate the development of Adaptive Leadership capacity in the respondents.

Self-Awareness (Sub-Theme 1). An overwhelming number of respondent perceptions identified the course as contributing to the development of self-awareness (89\%). Selfawareness is defined as the conscious understanding of one's internal feelings, dispositions, and perceptions and their origins (Andenoro, Popa, Bletscher, \& Albert, 2012). Respondents noted that an understanding of self is critical as they attempt to develop sustainable solutions for complex problems. "For me to make a difference in the world, I need to educate others about what I have learned in this class and continue to grow in my own education" (RE7). "The class really helped me to understand how I can use my specific skill set to help our world" (RA11). "I feel more knowledgeable and confident about communicating and sharing the challenge with people after taking the class" (RD12). "We must be self-aware to help others, so you must address your own issues before you can look outwards to help others" (RB22).

I am a [biology major] so my background in rooted in science. This class has taught me that although technological and scientific innovation is at the forefront of social progression, it is clear to me that the degree that we can apply scientific and technological innovation will be determined by the social elements. This [newly] found appreciation for the social factors will definitely make me approach the rest of my academic and my future professional career in a much different way than how I have in the past. This will push me to think differently and really engage in the social elements of the challenge. (RA6)

I think that this class has changed me in that I pay more attention to what's going on around me. I am thinking about others as much as I am thinking about myself. I am looking around me at my community, and I am seeing problems we are facing. For those who are thinking about changing the world, this is a great class to do that. (RD2)

I am going to use all of the information that I got from the professors, presenters, and my classmates to keep myself aware. I have found myself changing my behavior because of 
this class. [In addition], I am going to share my knowledge with others, which can hopefully contribute to their understanding of the issue. (RC15)

Intercultural Competence (Sub-Theme 2). Several respondents also provided perceptions identifying the course and accompanying educational methodologies as contributing factors to their development of intercultural competence (67\%). Intercultural competence can be defined as the ability to communicate and work with people from diverse contexts while valuing their cultural perceptions, ideologies, and traditions (Andenoro \& Bletscher, 2012). Respondents noted that it is critical to understand the people that they are attempting to work with to address complex problems. They shared that the critical elements of sustainability are grounded in behavioral shifts and community investment in the change based initiatives or innovation. "I realize that you can't just give people food, provide people with aid, or even build a local garden if we do not consider culture first" (RA15). "Before I judge someone who is food insecure it is critical for me to understand how they got there and what the root cause was" (RE21). "It really helped me to look at what other countries are doing compared to what we have here in the US. It gives me perspective of the privileges that we take for granted here" (RB5).

Different cultures and people do things for different reasons. In the future, I will not be so quick to judge. Really the first thing that we need to do in the future is to understand "why" before we try to help. (RD3)

There is no [single] solution to hunger, due to the diversity of our world. There are so many different people and this will take different solutions. We need to reach out to the people and ask them what they need versus barging in and telling them what they need. (RC28)

Collaboration (Sub-Theme 3). Several respondents identified the course as a contributing factor to their development and prioritization of collaboration (73\%). Collaboration can be defined as a group of people coming together to achieve synergistic outcomes (Lawrence, Hardy, \& Phillips, 2002). Respondents noted an appreciation for and a desire to collaborate to address complex problems. They detailed the ideas that collaboration deepens their understanding for the problem and creates opportunities for more sustainable solutions. "We all come from different angles and when we bring those together, we can find the solution" (RB36). "Respect leads to trust which leads to accompaniment, which is a foundation for creating cooperative partnerships" (RD16). "This course taught me that none of us can do it by ourselves. We need others, and together we have the potential for large-scale changes that can better our world" (RE35). I need to continue to share the issue with others, so I can impact how people behave. I know that because of this class I can communicate the problems in a much more powerful way that will hopefully bring about change in others. (RC19)

I realize that I cannot do it alone. I need others who are engaged in the challenge like I am. When we come together, we have the potential to share ideas and contribute to something way bigger that I could ever come up with by myself. (RD22) 
We are going to be in trouble if we do not start to work together more effectively. This class gave me the skills to work with together and get them to work on the challenge with me. Together, we could actually make a difference in the world. (RB31)

Communication (Sub-Theme 4). The development of effective communication skills was noted by almost all of the respondents as a critical outcome of the course (92\%). For the purposes of this paper, communication can be defined as the exchange of information between two or more people or things (Littlejohn \& Foss, 2010). "To change the world you have to change people's perceptions" (RE2). "For people to care about and impact the challenge, we have to know about the challenge and explain it effectively to them" (RB4). "It is really important to share the knowledge that we have and expand that knowledge" (RC8). "Communication among the systems is critical to us addressing the challenge. If we do not talk, there is no hope for a solution" (RA29).

I need to continue to share the issue with others, so I can impact how people behave. I know that because of this class I can communicate the problems in a much more powerful way that will hopefully bring about change in others. (RB9)

[The presenter] talked about understanding myself so I could share my perspectives more effectively with others. This really did create a foundation for working with others. I think that solid communication is really critical to saving our planet. (RA10).

When we began to talk in our groups, we began to develop new ways to think about the issue. Then when we heard the other presentations, we thought of a ton of other ideas. Just sharing your perspectives with one another is such a powerful way to start working towards a solution. (RC17)

Locus of Control (Sub-Theme 5). Internal locus of control was extended by the course, as students felt more engaged in the complex problems and communicated perspectives consistent with agency for addressing the challenge (90\%). Evolving out of Rotter's (1954) original idea, locus of control can be defined as a person's belief that they are in control of what happens (Davenport, 2010). Individuals that exhibit high degrees of internal locus of control tend to be more assertive and confident. They actively seek out information that is of benefit to them in pursuit of their own objectives. They actively seek chances for achievement (2010). Respondent perceptions aligned with this noting that they felt empowered by the course and the accompanying educational methodologies to address the complex problems and create solutions to mitigate them. "This class has changed me and hopefully now I can change the lives of others" (RB2). "I learned about what is out there. These perspectives gave me a foundation for finding a solution" (RD4). "This course provides a foundation for me to be more engaged. It really opens doors for me to be more active in my community and shifts how I interact with people around me" (RE1). "Often times, I would leave class overwhelmed or confused about the problem, but it is reassuring to know that we have people addressing these issues and I am one of them" (RE33). 
I need to continue to share the issue with others so I can impact how people behave. I know that because of this class I can communicate the problems in a much more powerful way that will hopefully bring about change in others. (RD13)

I plan for the future understanding that I can contribute to solving the global food crisis. Maybe as an environmental scientist or a small agri-business owner, but I know that because I am educated about this, I have to do something about this in the future. (RB17)

Development of Systems Thinking. Respondents identified that the class and the accompanying educational methodologies are contributing to the development of systems thinking, which is a fundamental component of addressing complex adaptive problems (76\%). Systems thinking can be defined as an understanding of the interconnectedness among processes that influence one another to create a synergistic impact on the whole (Senge, 1990). Respondents noted that by using the five systems (i.e., Social, Environmental, Economic, Food, and Health) presented in class they were able to gain a deeper understanding of the context and the problems. Further, they provided that if they do not consider the systems impacted by a given problem, they are at a severe disadvantage for mitigating that problem. "Through systems thinking we can begin to depoliticize the issues that we face" (RE5). "Food security is not a one sided issue. It is interconnected by various systems that make it a complicate issue to address. But the systems also provide us with the solution" (RB7). "I had not heard of systems thinking before [the course], but this is something that I can use for the rest of my life" (RE11). "It is so important to look at how the systems are intertwined within the complexity of the challenges" (RC14). "If you are thinking about systems, it is critical to consider that each system impacts the others. So if you are thinking about solutions you first have to be thinking about systems" (RA4).

Systems thinking is incredibly important because when we did our systems presentation we realized that it is impossible not consider the other systems and how they impact the whole of the problem. (RC8)

The social issues associated with the challenges are really powerful. Consider that if you give someone food at a farmers market, they may not have the means to get it home due to transportation issues. Hence it is critical to consider the how everything is affected by what we do and how we do it. (RE18)

Empowerment of Agency. Respondents identified that the course and accompanying educational methodologies are contributing to their empowerment as action-oriented advocates with attitudes and behaviors critical for addressing complex problems (71\%). Grounded in the work of Emirbayer and Mische (1998), the empowerment of agency can be defined as the development of the motivation and resulting action strategically directed at impacting change with respect to complex adaptive challenges. For the purposes of this paper the authors have aligned agency with social responsibility and "triple bottom line" thinking (Norman \& MacDonald, 2004). Respondents shared perceptions that they can impact local and global change affecting complex problems. They also noted their understanding of how their behaviors impact their organizations, the communities, and the environment. Specifically, respondents noted that the course and accompanying educational methodologies have helped them to understand that their actions can have profound consequences for addressing complex problems and that they 
now have a willingness and desire to act accordingly. "It definitely broadened my way of thinking and showed me that I can make a difference" (RC19). "Regardless of your role you can contribute to the solution. Whether you are a doctor, stay at home mom, or anything else, you have the power to contribute to a better tomorrow" (RA12).

Learning about the challenges we will face in the future is disheartening at times, but we will overcome. At first I thought, what can I do? But this is a team effort and we are not going to see change overnight. However, sustainability is possible through incremental changes and the potential for a better tomorrow is real. (RE3)

[It] is not a quick fix, but that doesn't mean that we shouldn't address it. This is inspiring for me because I have to consider how I can make the biggest impact based on who I am. (RD7)

The Impact of the Authentic Audience \& Authentic Challenge. Respondents identified that the authentic audience and authentic challenge are forcing them to think more deeply about complex problems (62\%). Authentic audience can be defined as community or corporate based stakeholders external to the university system who hold decision-making capacity with respect to a given problem. An authentic challenge can be defined as a dynamic problem or issue, whose solution can have tangible application within human contexts. Authentic challenges can be both technical and linear or complex and interdependent. Respondents noted that the authentic challenges provided context for real world problems, citing that they were more engaged because the situations were ongoing and that they had the potential to contribute to something beyond the course. They also shared that the authentic audiences extended their understanding and project outcomes to provide implications for real people. "The policy makers and industry professionals made it real. I felt the pressure to provide quality because [my work] could help real people" (RE23). "These are real problems affecting real people. This made me work harder because this is about more than a grade when real people are involved" (RA5).

One of the coolest parts of the class was the group project because we got to work in groups and practice groups dynamics, but more than that we got to work on a real life problem. It wasn't just some hypothetical situation and you can take that further. That is what I really liked about it, we got to show real people, important people what we are capable of doing. (RD26)

Due to the realness of the challenge, I feel it is critical to look at the social and individual identities of those that we work with. This leads to social responsibility and I feel like I am more engaged in the community, because I know who they are. (RB14)

The guest speakers contextualized the rationality and emotion that exists within each of their disciplines for the issue. This was really powerful for me, because it made me think that real people are working on this real issue. It is crazy to think that I can contribute to what they are do, but I can and that is pretty cool. (RA18)

The most important thing that we have learned is to watch for the interconnectedness that exists among the systems. I mean, you have to consider the culture and identity of the 
people that we hope to work with. This is critical if we ever hope to really help anyone. We need to open up our minds to the systems thinking that will provide us with opportunities in the future. These are real people with real issues, so if we want to help, we better engage in a very real way. (RD22)

\section{Discussion \& Conclusions}

Leadership educators are faced with an array of dynamic and ever-changing variables within the landscape of practical leadership. This forces a shift in leadership learning that includes the development of innovative educational methodologies aimed at the development of capacities and dispositions targeting the issues future leaders will need to address. Based on the analysis of the findings, the use of authentic audience and authentic challenge and innovative teaching methods can create a distinct advantage for leadership educators attempting to develop Adaptive Leadership capacity and Socially Responsible Agency in interdisciplinary undergraduate learners. While future research should include the inclusion of instrument development and the accompanying exploration of generalizability of the innovative methods to leadership learning contexts, it is evident that the findings are transferable to similar leadership learning contexts and have the potential to benefit leadership learners.

The authors present the following conceptual framework based on a synthesis of the literature and findings that leads to development of Socially Responsible Agency and complex Adaptive Leadership capacity in interdisciplinary undergraduate leadership learners. (See figure 1).

Process

Outcomes
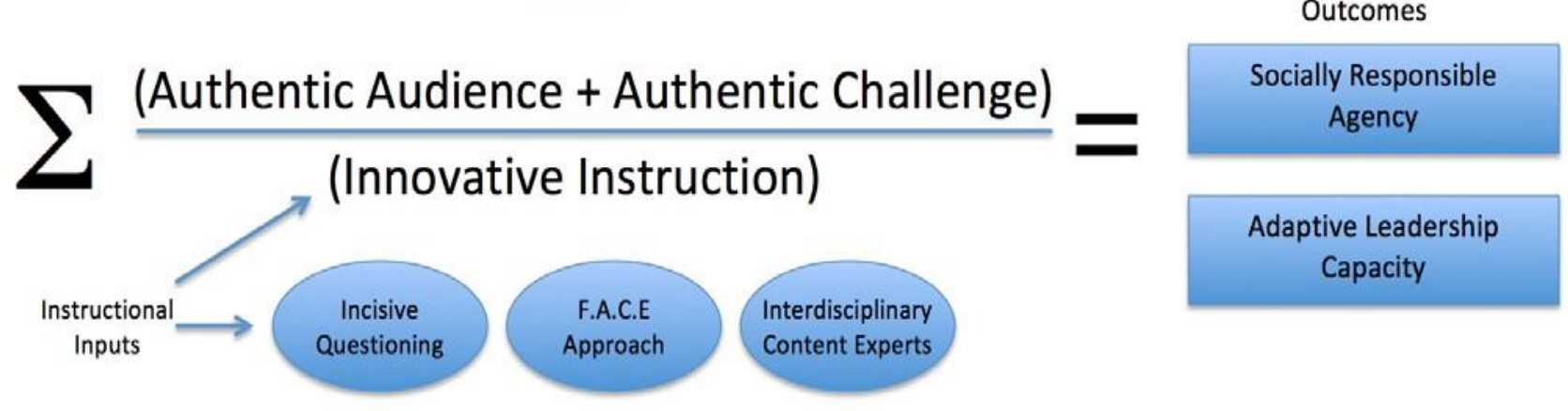

Figure 1. Complex Problem Conceptual Learning Framework.

The conceptual model depicts a horizontally progressive process grounded in innovative instructional inputs, which ultimately leads to significant outcomes laden in human capacity building. Within the model, sigma represents the sum of the formula's parts. This is critical as the authors purport that each piece of the model plays a critical role in the development of the outcomes in the leadership learner. Further, the horizontal bar dividing the sum of authentic 
audience and authentic challenge and innovative instruction serves two purposes. First, it demonstrates the supportive nature of innovative instruction for inclusion of the authentic audience and authentic challenge. It implies the purposive nature of the instruction in the process. Second, the bar demonstrates the divisive potential of instruction for the process. If innovative instruction fails to create a supportive yet challenging environment grounded in the ambiguity of the authentic challenge, the potential for reaching the desired outcomes is significantly diminished. Grounded in a synthesis of the literature and findings, the conceptual model provides a dynamic opportunity for leadership educators to develop Socially Responsible Agency and Adaptive Leadership capacity in leadership learners.

It is recommended that leadership educators attempting to use this innovation consider process over content. While authentic challenges should be presented with supporting empirical evidence and credible narratives, the facilitation of the process is equally important. Incisive questioning and the F.A.C.E. Method (C) provide context for the facilitation of this. However, as with any process grounded in counseling psychology and psychotherapy, it is critical that the leadership educator takes a constructive and intentional approach to unpacking the learners' emotions and their connections to the authentic challenges.

When used skillfully, this innovative approach can provide leadership educators with the impetus to go beyond the traditional educational methods of "open head, dump in knowledge" and explore new areas of learning immersed in affective shifts and behavioral changes. The approach serves as a powerful tool, equipping leadership learners with social science capacities and dispositions, which can be applied in complex adaptive ways to seemingly technical and linear problems. This integrated approach allows for interdisciplinary connections to be made by leadership learners, which have the potential to lead to transdisciplinary outcomes and sustainable solutions that have far reaching implications for our world.

\section{References}

Alexandratos, N., \& Bruinsma, J. (2012). World agriculture towards 2030/2050: The 2012 revision. ESA Working paper No. 12-03. Rome, Italy: FAO.

Andenoro, A. C., Allen, S. J., Haber-Curran, P., Jenkins, D. M., Sowcik, M., Dugan, J. P., \& Osteen, L. (2013). National Leadership Education research agenda 2013-2018: Providing strategic direction for the field of leadership education. Retrieved from Association of Leadership Educators website: http://leadershipeducators.org/ResearchAgenda.

Andenoro, A. C., Baker, M., Stedman, N. L. P., \& Weeks, P. P. (2016). Addressing complex problems. In T. G. Roberts, A. Harder, \& M. T. Brashears, (Eds). (2016). American Association for Agricultural Education national research agenda: 2016-2020. (p. 57-66). American Association of Agricultural Education. 
Andenoro, A. C., Bigham, D. L., \& Balser, T. C. (2014, July). Addressing global crisis: Using authentic audiences and challenges to develop Adaptive Leadership and Socially Responsible Agency in leadership learners. Proceedings of the Association of Leadership Educators, San Antonio, TX.

Andenoro, A. C., \& Bletscher, C. G. (2012). Transforming the international learning experience for students: Moving beyond the principle of accompaniment. Journal of Leadership Studies, 6(1), 52-57.

Andenoro, A. C., Popa, A. B., Bletscher, C. G., \& Albert, J. (2012). Storytelling as a vehicle for self-awareness: Establishing a foundation for intercultural competency development. Journal of Leadership Studies, 6(2), 102-109.

Balser, T. C., Bigham, D. L., \& Andenoro, A. C. (February, 2014). Humanity's 2050 challenge: Using authentic challenge and audience to promote social responsibility. Poster session presented at the Lilly Conference on College and University Teaching and Learning: Evidence Based Teaching and Learning. Newport Beach, CA.

Banerjee, S. B. (2006). Corporate Citizenship, Social Responsibility and Sustainability: Corporate Colonialism for the New Millennium. In J. Jonker, \& d. W. Marco, The Challenge of Organizing and implementing corporate Social Responsibility, 31-47. Palgrave Macmillan: New York, NY.

Berger, M., \& Finkbeiner, M. (2013). Methodological challenges in volumetric and impactoriented water footprints. Journal of Industrial Ecology, 17(1), 79-89.

Berman, S. (1990). Educating for social responsibility. Educational Leadership, 75.

Brown, L. R. (2012). Full planet, empty plates: The new geopolitics of food scarcity. New York, NY: W. W. Norton Company Inc.

Carver, R. (1996). Theory for practice: A framework for thinking about experiential education. Journal of Experiential Education, 19, 8-13.

Charmaz, K. (2014). Constructing grounded theory. Thousand Oaks, CA: Sage Publications Inc.

Corbin, J., \& Strauss, A. (2008). Basics of qualitative research: Techniques and procedures for developing grounded theory. Thousand Oaks, CA: Sage Publications Inc.

Davenport, J. (2010). Leadership style and organizational commitment: the moderating effect of locus of control. In Proceedings of ASBBS Annual Conference, Las Vegas, NV. 277-282.

Dewey, J. (1938). Experience \& education. New York, NY: Simon \& Schuster.

Dooley, L. M. (2002). Case study research and theory building. Advances in Developing Human Resources. 4(3), 335-354. 
Emirbayer, M., \& Mische, A. (1998). What is agency?. American journal of sociology, 103(4), 962-1023.

Emmott, S. (2013). Ten billion. New York, NY: Vintage Books.

Eriksson, P., \& Kovalainen, A. (2008). Qualitative research in business studies. Thousand Oaks, CA: Sage Publication Inc.

Erlandson, D. A., Harris, E. L., Skipper, B. L., \& Allen, S. D. (1993). Doing naturalistic inquiry: A guide to methods. Newbury Park, CA: Sage Publications, Inc.

Estes, C. A. (2004). Promoting student-centered learning in experiential education. Journal of Experiential Education, 27(2), 141-160.

Flick, U. (1992). Triangulation revisited: Strategy of validation or alternative? Journal for the theory of social behaviour, 22(2), 175-197.

Giles, D. E., \& Eyler, J. (1994). The theoretical roots of service-learning in John Dewey: Toward a theory of service-learning. Michigan Journal of Community Service Learning, 1(1), 7785 .

Glaser, B. G. (1978). Theoretical sensitivity: Advances in the methodology of grounded theory. Sociology Pr.

Glaser, B. G., \& Strauss, A. L. (1967). The discovery of grounded theory. Hawthorne, NY: Aldine.

Heifetz, R. A., Grashow, A., \& Linsky, M. (2009). The practice of Adaptive Leadership: Tools and tactics for changing your organization and the world. Cambridge, MA: Harvard Business Press.

Heifetz, R. A., \& Laurie, D. L. (1997). The work of leadership. Harvard business review, 75, 124-134.

Heifetz, R. A. \& Linsky, M. (2002). Leadership without easy answers. Cambridge, MA: Harvard University Press.

Hobbs, C. K., \& Tsang, H. H. (2014, May). Industry in the Classroom: Equipping Students with Real-World Experience A reflection on the effects of industry partnered projects on computing education. In Proceedings of the Western Canadian Conference on Computing Education (p. 7). ACM.

Katula, R. A., \& Threnhauser, E. (1999). Experiential education in the undergraduate curriculum. Communication Education, 48(3), 238-255. 
Kayes, A. B., Kayes, D. C., \& Kolb, D. A. (2005). Experiential learning in teams. Simulation \& Gaming, 36(3), 330-354.

Kline, N. (1999). A time to think. London, UK: Ward Lock, Cassell Illustrated.

Kolb, D. A. (2014). Experiential learning: Experience as the source of learning and development. Upper Saddle River, NJ: FT press.

Kolb, D. A. (1984). Experiential learning: Experience as the source of learning and development (Vol. 1). Englewood Cliffs, NJ: Prentice-Hall.

Krippendorff, K. (2012). Content analysis: An introduction to its methodology. Thousand Oaks, CA: Sage Publications.

Lawrence, T. B., Hardy, C., \& Phillips, N. (2002). Institutional effects of interorganizational collaboration: The emergence of proto-institutions. Academy of Management Journal, 45(1), 281-290.

Lewin, R., \& Regine, B. (2003). The core of adaptive organizations. In E. Mitleton-Kelly (Ed.), Complex systems and evolutionary perspectives on organizations: The application of Complexity Theory to organizations (pp. 167-184). London: Pergamon.

Lichtenstein, B. B., Uhl-Bien, M., Marion, R., Seers, A., Orton, J. D., \& Schreiber, C. (2006). Complexity leadership theory: An interactive perspective on leading in complex adaptive systems. Emergence: Complexity and Organization, 8(4), 2-12.

Littlejohn, S. W., \& Foss, K. A. (2010). Theories of human communication. Waveland Press.

Marion, R., \& Uhl-Bien, M. (2001). Leadership in complex organizations. The Leadership Quarterly, 12(4), 389.

McCoy, D., Montgomery, H., Arulkumaran, S., \& Godlee, F. (2014). Climate change and human survival. BMJ, 348(mar26 2), g2351.

Miettinen, R. (2000). The concept of experiential learning and John Dewey's theory of reflective thought and action. International Journal of Lifelong Education, 19(1), 54-72.

Norman, W., \& MacDonald, C. (2004). Getting to the bottom of" triple bottom line". Business Ethics Quarterly, 243-262.

Rotter, J. (1954). Social learning and clinical psychology. Englewood Cliffs, NJ: Prentice-Hall.

Senge, P. (1990). The leader's new work: Building learning organizations. Sloan Management Review, 32(1), 7-23. 
Stedman, N. L. P. \& Andenoro, A. C. (2015). Emotionally engaged leadership: Shifting paradigms and creating adaptive solutions for 2050. In M. J. Sowcik, A. C. Andenoro, M. Mcnutt, \& S. Murphy (Eds.), Leadership 2050: Contextualizing Global Leadership Processes for the Future (p. 147-159). Bingley, West Yorkshire, UK: Emerald Group Publishing.

Uhl-Bien, M., \& Marion, R. (2008). Complexity leadership (Vol. 5). Charlotte, NC: Information Age Publishing.

United Nations Human Settlement Program. (2015). UN-habitat urban data [Data file]. Retrieved from http://urbandata.unhabitat.org/.

United Nations, Department of Economic and Social Affairs, Population Division. (2015). World Population Prospects: The 2015 Revision, Key Findings and Advance Tables. Working Paper No. ESA/P/WP.241.

Yukl, G., \& Mahsud, R. (2010). Why flexible and Adaptive Leadership is essential. Consulting Psychology Journal: Practice and Research, 62(2), 81.

Zadek, S., Forstater, M., \& Yu, K. (2012). Corporate responsibility and sustainable economic development in China: Implications for business. US Chamber of Commerce. 